\title{
La derecha mexicana en los años veinte: tradición católica y conservadurismo
}

\author{
Javier Mac Gregor Campuzano*
}

Recibido: 27 de diciembre de 2019

Dictaminado: 22 de abril de 2020

Aceptado: 21 de agosto de 2020

\section{RESUMEN}

El artículo estudia la forma en que se organizó, en la década de 1920, la corriente política mexicana caracterizada como de derecha, bajo distintas denominaciones, centrándose en las agrupaciones que, desde finales de la década anterior, participaban en los distintos niveles de la vida política nacional: electoral, parlamentario, territorial, etcétera. En este panorama, llama la atención la aparición de múltiples personajes (Palomar y Vizcarra, Capistrán Garza, Diego Arenas Guzmán, Rafael Ceniceros y otros), que con diversa intensidad participaron en las organizaciones de derecha hasta conformar la Liga Nacional de Defensa de la Libertad Religiosa, la cual estalló la guerra en contra del Estado mexicano hacia mediados de 1926 hasta concluir en los arreglos de junio de 1929. El artículo se sustenta en la bibliografía más actualizada sobre el tema, así como en un conjunto de fuentes primarias de enorme utilidad.

Palabras clave: política, partidos, derecha, conservadurismo, politicos. 


\title{
The mexican political right in the twenties: Catholic tradition and conservatism
}

\begin{abstract}
The article studies de way in which the political current called "the right wing", organized in Mexico under different denominations all along the second decade of the XXth. Century. This analysis enfatizes the organizations that participated in the national political life at different levels: in election, in the Congress, in the territorial movements, etc. The interesenting thing in this landscape is the presence of some political actors (Palomar y Vizcarra, Capistrán Garza, Rafael Ceniceros, Diego Arenas Guzmán, etc.) who appears with different degrees in this organizations, which will flow in the National League for the Defense of the Religious Freedom. This will declare war to the Mexican State since 1926 till mid-1929, when the "arrengments" were obtained. This work is based in the main bibliography on the subject, and also uses some primarial sources of great interest and utility.
\end{abstract}

Key words: politics, parties, right wing, conservatism, politicians.

\section{INTRODUCCIÓN}

La ilusión de que no existe se debe a que la derecha en México no se encuentra solo - ni siquiera principalmente - a la derecha del poder central del 'gobierno de la Revolución mexicana'. La derecha está simultáneamente en el poder y en la oposición, en el gobierno y en la sociedad. Roger Bartra, Viaje al centro de la derecha, p. 52.

\footnotetext{
Caracterizar a una corriente política del México de la década de 1920 como de derecha sería sencillo si el esquema dicotómico tuviera algún sentido para explicar la geografía de la política durante aquellos años. Pero no lo tiene. A la afirmación recurrente de que sólo los "revolucionarios" podían ser parte de los círculos del poder de la nueva élite política formada a partir del triunfo de la Revolución de 1910, pero consolidada durante la década siguiente, se oponía la acción de grupos y movimientos que pugnaban por ampliar su papel, y, en el caso de los sectores más conservadores, por combatir y modificar el
} 
rumbo político del país, que tenía como faro institucional a la Constitución firmada en Querétaro en febrero de 1917. Sin embargo, concuerdo con Bartra en que la dicotomía entre revolucionarios y reaccionarios, nosotros y ellos, es una imagen discursiva falsa, que sólo tiene pretensiones legitimadoras y no encuentra correspondencia con la realidad de esos años; es más, a menudo choca con ésta.

La presencia de los miembros de la familia revolucionaria, como se autocaracterizaban, con intereses económicos cada vez más definidos y extensos, o con ambiciones políticas que no podían ser canalizadas a través de los medios formales de participación en la arena política institucional (no había cargos relevantes para todos), generó manifestaciones frecuentes de descontento, principalmente militares: los generales Mario Ferrer, Miguel Alemán, Juan Carrasco, Cástulo Pérez, Guadalupe Sánchez, Arnulfo Gómez y muchos otros, pese a su formal adscripción al grupo de los revolucionarios, en realidad representaban los intereses de la estirpe más conservadora y luchaban - muchas veces, llegando a morir- contra el régimen.

En general, la izquierda, principalmente comunista o anarquista, no significó una preocupación seria para el gobierno revolucionario durante esta década, en lo que se refiere a la búsqueda del poder político o a un serio trastrocamiento del orden constitucional (no me refiero aquí a su importancia en la organización de movimientos campesinos o a su papel en la organización obrera).

La promulgación de la Constitución en 1917, con su enorme significado por la incorporación de derechos sociales e individuales, generó una reacción inmediata entre los sectores conservadores, en particular los vinculados con la jerarquía católica, pues tales derechos afectaban directamente a sus intereses. De acuerdo con Carmen Collado, "el anticlericalismo revolucionario se expresó a través de la separación completa de la Iglesia y el Estado", y esto generó una clara disputa por la lealtad de los ciudadanos. ${ }^{1}$

Pero la tensión, naturalmente, no apareció de manera súbita el 5 de febrero de 1917, sino que se venía gestando desde mucho antes. No viene al caso remontarnos al siglo XIX para explicar los efectos que tanto las Leyes de Reforma como la Constitución de 1857 tuvieron sobre estas relaciones, pero cabe mencionar que se pudo establecer entre el régimen porfirista y la Iglesia un estado de "conciliación", el cual fue sacudido violentamente por el estallido revolucionario en 1910, caracterizado — como han visto algunos autores - por un "anticlericalismo radical". Esto, una vez resuelta la fase armada entre los partidarios de la Convención y los constitucionalistas, a favor de los últimos, quedó marcado en el texto constitucional: 
El artículo $3^{\circ}$, relativo a la educación, impide la participación del clero en la instrucción primaria y secundaria, así como la destinada a normalistas, obreros y campesinos. El artículo $5^{\circ}$ prohíbe el establecimiento de órdenes monásticas. El 24 prohíbe los actos religiosos fuera de los templos. El 27 impide a las Iglesias la adquisición, posesión y administración de bienes raíces y el 130 no reconoce personalidad jurídica 'a las agrupaciones denominadas iglesias', y restringe absolutamente las actividades sociales y políticas de los ministros de cultos. ${ }^{2}$

Éste fue el punto central del choque permanente. Como menciona Roberto Blancarte, "en el terreno político, la vigencia o transformación de los artículos constitucionales se convierte en el punto esencial del conflicto entre Iglesia y Estado". ${ }^{3}$

La visualización y el análisis de esta tensión, sin embargo, se complejiza cuando aparecen actores que, sin ser propiamente adversarios activos al marco constitucional, devienen opositores al orden establecido por la familia revolucionaria - a la cual, en algún momento, pudieron estar integrados-, y que, por lo mismo, son caracterizados como reaccionarios, como fue el caso de Luis Cabrera y José Vasconcelos (o de Juan Sánchez Azcona y Diego Arenas Guzmán, a quienes estudiaré aquí): “aunque la Revolución los consideró reaccionarios, sus críticas no corresponden [al menos durante la década de 1920] a lo que se podría considerar un verdadero proyecto conservador, reaccionario o, propiamente, de 'derecha"'. ${ }^{4}$

El objetivo de este artículo es mostrar la forma en la que se constituyeron las más importantes organizaciones de derecha de nuestro país, para influir de manera significativa en la definición del rumbo político del mismo. El principal eje del análisis consiste en el seguimiento de la actuación de determinados personajes que aparecen recurrentemente en la integración y actuación de las agrupaciones. Para ello, parto de la idea desarrollada por Soledad Loaeza (basada en Ernest Nolte) de que la derecha siempre surge como una respuesta política - en este caso, al régimen revolucionario y a los principios establecidos por el constituyente de 1917—, y que esto le imprime un carácter defensivo. Sin embargo, continúa Loaeza, "en situaciones críticas [esta derecha] asume estrategias de ataque [...] y desarrolla cierta autonomía que se expresa en proyectos políticos aparentemente constructivos". 51

Blancarte, "Modernidad", p. 155.

Ibid., p. 157.

Barrón, "Conservadores", p. 438. En su momento, Vasconcelos - como no podía ser de otra manera - comentaba inteligentemente a principios de 1929: "me llaman reaccionario aquellos mismos que de la Revolución han sacado los latifundios y los palacios". Ibíd., p. 450 .

5 Loaeza, "Conservar", p. 31. Por ejemplo, Jean Meyer señala que la Liga de Defensa de la Libertad Religiosa nació como una reacción de defensa, se convirtió en un movimiento 
análisis que aquí presento cruza toda la década de 1920, pues abarca desde el inicio de la institucionalización sonorense, en ese año, hasta la conclusión de la Guerra Cristera mediante los arreglos de 1929, momento a partir del cual esta oposición comienza una nueva etapa.

Sin duda, el caso mexicano fue peculiar en el contexto político latinoamericano de la tercera década del siglo xx, pues el fenómeno de la Revolución mexicana cruzó y marcó profundamente la conformación y el desarrollo de todo el proceso político nacional. ${ }^{6}$ La Constitución de 1917 se convirtió en el referente político fundamental para el entramado de todos los aspectos económicos, judiciales, sociales e institucionales del país. A través de las normas, a decir de Pedro Salazar, los juristas se propusieron transformar la convivencia; sin embargo, enfatiza el autor, las normas, más que el mero marco de nuestra convivencia, son su molde. De esta forma, "las constituciones postulan los principios que dan identidad al Estado que las adopta". ${ }^{7}$ En este caso, como una república representativa, democrática y federal.

Según veíamos en párrafos anteriores, en México se establecieron una serie de principios normativos tendientes a regular tanto las relaciones entre la Iglesia y el Estado, como la influencia de aquélla sobre el conjunto social. Esto, sumado a lo que se consideraba — desde la época del constitucionalismo- como una política persecutoria contra la jerarquía, generó continuas manifestaciones de rechazo por parte de la Iglesia como institución y de muchos de sus feligreses. El reto no era menor. Dos autores clarifican el tamaño del desafío para el Estado que se encontraba, primero, en pleno proceso de reconstitución y, luego, de institucionalización política plena. Roberto Blancarte reflexiona sobre el aspecto que mayor preocupación podía generar a los estadistas del régimen revolucionario: "la iglesia católica en México cuenta [entonces] con una doctrina social que se constituye en un modelo alternativo de organización social y con los elementos materiales, pero sobre todo humanos, que le permitirán hacer frente a las embestidas del régimen a lo largo del siglo Xx". ${ }^{8}$ A esta idea, Marta Eugenia García Ugarte agrega cómo la nueva clase política — pero particularmente Calles — visualizaba esta amenaza:

Calles consideraba a los católicos como un grupo político con raíces profundas en la nación mexicana. Se trataba de una fuerza política real que si lograba articular sus demandas de tipo religioso con las demandas políticas de los revolucionarios

político y "pasó de la defensiva a la ofensiva con la firme intención de tomar el poder y ejercerlo por entero". Meyer, La cristiada 1, p. 50.

6 Acerca de la particularidad del caso mexicano en el contexto iberoamericano, véase Lida, Bohoslavsky y Jorge, Las derechas.

Salazar, "Longeva", p. 4.

Blancarte, "Modernidad", p. 155. Cursivas mías. 
que estaban inconformes con el régimen de los sonorenses, podría efectivamente conducir al desastre la frágil estabilidad política y social. ${ }^{9}$

De esta forma, ante el reconocimiento mutuo de la fuerza del antagonista, y ante la creencia plena en la justeza de sus convicciones, la relación del Estado con los sectores aliados a la jerarquía eclesiástica, así como con los grupos desafectos al régimen en general ofrecerán una década en la que el choque se manifestará de múltiples maneras: desde la participación opositora en los procesos electorales, pasando por la agrupación bajo modelos políticos importados (por ejemplo, el fascismo), hasta la preparación de la guerra abierta, que se presentó bajo el conflicto cristero, entre 1926 y 1929.

En este artículo estudiaré la conformación y presencia de las fuerzas que podemos considerar como conservadoras o de derecha, "reaccionarias" para el Estado, ${ }^{10}$ a partir de la acción de algunos actores específicos. Personajes como Rafael Ceniceros, Miguel Palomar y Vizcarra, René Capistrán Garza, Juan Sánchez Azcona, Diego Arenas Guzmán y Guillermo Pous aparecieron en los principales grupos y organizaciones, y crearon una red de relaciones políticas cuya acción, bajo distintas modalidades, se desarrolló en el transcurso de toda la década. Dichos cuerpos políticos fueron: el Partido Católico Nacional, la Asociación Católica de la Juventud Mexicana, la Liga Democrática, el Partido Nacional Republicano, el Partido Fascista, la Liga Política Nacional, así como aquella agrupación en la cual confluyeron, de cierta forma, todas éstas: la Liga Nacional de Defensa de la Libertad Religiosa, fundada en 1925, la cual preparó y estalló el conflicto bélico que dominaría durante toda la segunda mitad de la década. El grado de vinculación de estos personajes con las organizaciones o los grupos declaradamente de derecha fue variado, pero todos manifestaron su oposición a las políticas del gobierno, ya fueran anticlericales o de otro tipo.

\section{Los partidos y las organizaciones políticas}

Adolfo de la Huerta y aquellos individuos que por ser ya verdaderos desechos de la revolución no han tenido más remedio que seguir siendo delahuertistas, han decidido por indicación del propio de la Huerta, entrar en un periodo de aparente actividad, con el objeto de querer demostrar que el delahuertismo no ha fracasado, y que se les tome en cuenta en un

9 García Ugarte, "Los católicos", p. 131.

10 Un importante estudioso del pensamiento conservador en México, como lo fue Gastón García Cantú, equipara el concepto de derecha al de reacción. García Cantú, El pensamiento. 
gran movimiento político-revolucionario que en la mente de ellos existe, dizque está siendo

preparado o está próximo a preparase para derrocar a nuestro gobierno; en cuyo movimiento, según estos individuos, tomará parte muy activa el antiguo elemento reaccionario de México ayudado por el Clero Católico, y Capitalistas Mexicanos y Extranjeros, que nunca han estado conformes con la Constitución de 1917.

Agente No. 47 al Jefe del Departamento. San Antonio, Texas, 11 de junio de $1926 .{ }^{11}$

Los principios establecidos en la Constitución de 1917 encontraron sus posibilidades de aplicación y su proceso de reglamentación plena en sus diversos ámbitos constitutivos -agrario, laboral, educativo, judicial, municipal-, hasta que el grupo de los sonorenses pudo comenzar a sentar las bases de un desarrollo político institucional cabal, a partir de 1920. El gobierno de Carranza, formalizado tras su triunfo electoral en marzo de 1917, en general contemporizó con la Iglesia en cuanto a la aplicación de los preceptos que más le inquietaban, y logró mantener una situación de relativa estabilidad en este plano, pues ya bastante complicados eran los demás (Congreso, ejército, Estados Unidos, compañías petroleras, movilización campesina y obrera). En general, la política de "conciliación" — que, como ya mencioné, había sido característica del Porfiriato, en términos de la relación Estado-Iglesia- se mantuvo durante este período. Incluso, durante el interinato delahuertista y el gobierno de Obregón la aplicación de los artículos constitucionales en este ámbito más espinosos permaneció en una especie de impasse. Con Calles, como ya lo indiqué, el conflicto abierto estalló y asumió la forma de una guerra que tendría enormes costos humanos y materiales para el país.

En términos de los partidos y las organizaciones políticas caracterizados como de derecha, esta década se puede analizar mediante dos procesos de sucesión presidencial en 1920 y 1924, el estallido de la Guerra Cristera en 1926 y el vínculo —ya más bien débil— de algunos actores con el antirreeleccionismo de 1927 y 1929; todo, naturalmente, acompañado de sus antecedentes y procesos paralelos, que iban desde actos de violencia capilar cotidiana $^{12}$ hasta atentados de todo tipo contra quienes eran considerados

AGN/DIPS, 310-1, Caja 2030B, Exp. 1, 6 fs.

12 Me refiero a incidentes como el siguiente: "Nuestro buen Chucho González tuvo la pena de perder casi al mismo tiempo a su abuelita y a su hermano. Este último en forma bien desagradable por cierto: cuando fue a tomar un inventario de los cuadros del Convento de Guadalupe, Zac[ateca]s. En virtud de haber sido nombrado Inspector de Monumentos 
como causa de la provocación (por ejemplo, los atentados dinamiteros contra Obregón, como candidato reeleccionista en 1927). Para ello, hay que examinar los antecedentes en algunas organizaciones importantes.

\section{El Partido Católico Nacional. Dios, Patria y Libertad}

El anuncio oficial de la creación del Partido Católico Nacional (PCN) se dio el 7 de mayo de 1911, bajo una serie de principios generales, tales como aceptar las instituciones políticas vigentes; respetar la Constitución de 1857, pero buscando derogar las Leyes de Reforma; establecer un programa de reforma social bajo los principios de la Rerum Novarum, y constituirse en un partido político moderno. ${ }^{13}$ El objetivo general establecía que, en la búsqueda de los dos bienes supremos, la justicia y la libertad, los católicos necesitaban ejercer sus "derechos políticos como ciudadanos [...], en el terreno de la legalidad". ${ }^{14}$ Más adelante, en febrero de 1912, se manifestaba la que era su preocupación central, y que contrastaba con el estado de cosas que se había logrado establecer durante el régimen anterior:

El socialismo no existía entre nosotros hasta la caída de la Dictadura, ni menos en su forma más grosera, agresiva y odiosa: el anarquismo. La imprudencia de los tribunos revolucionarios, la de cierta prensa poco advertida y las venenosas doctrinas de la que se inspira en la aversión a Dios y a la Iglesia, han hecho germinar y medrar en las masas populares, no el odio al rico, ya antes latente, pero sí las aspiraciones exorbitantes y absurdas a reformas sociales, que el principio sagrado de propiedad y la moral cristiana reprueban de consuno. ${ }^{15}$

La expansión del Partido Católico fue vertiginosa, y pronto llegó a tener a casi medio millón de adherentes en toda la República; ${ }^{16}$ por otro lado, su participación electoral en las elecciones legislativas de junio de 1912, para la integración de la XXVI Legislatura, se puede considerar exitosa, aun cuando

Artísticos, fue asaltado por un grupo de viejas instigadas por Caballeros de Colón y fanáticos, y recibió fuerte golpe en el vientre y una herida de puñal en el costado, a consecuencia de las cuales murió el dos del actual”. Archivo M. Gómez Morín, 572-1810. México, D.F. 17 de diciembre de 1921. Roberto Casas Alatriste a Manuel Gómez Morín.

13 O’Dogherty, "El Partido", pp. 207-209.

14 "Programa del Partido Católico Nacional". Mayo de 1911, en Planes en la Nación Mexicana, vol. 7, pp. 96-97. Respecto al Programa del Partido, Laura O'Dogherty comenta que, "a su declaración de filiación liberal, seguía un programa marcado por el antiliberalismo". O'Dogherty, "Dios", p. 125.

15 "Manifiesto al Partido Católico Nacional y a todo el pueblo de México". 5 de febrero de 1912, en Ulloa y Hernández, Planes, Libro 7, pp. 170-172.

16 Adame, El pensamiento, p. 174. Esta cifra puede parecer exagerada, pero no tengo forma de contrastarla. 
- como lo demuestra François-Xavier Guerra - la discusión en el Colegio Electoral le restó de manera arbitraria varias diputaciones, "ya que se trataba de impedir que la oposición de la mayor parte del país a las leyes anticlericales (denominador común de la ideología liberal mexicana) pudiera encontrar una salida política". ${ }^{17}$ El valor dado al criterio político por sobre el legal, echado a andar de manera implacable por Luis Cabrera y otros, le restó fuerza numérica a la representación católica dentro del Congreso. ${ }^{18}$

El PCN tuvo una existencia efímera, pues suspendió sus actividades en abril de 1914, principalmente por la "cancelación de espacios de participación política en el régimen de Huerta”, como explica O’Dogherty. ${ }^{19}$ En los inicios de esta agrupación, Miguel Palomar y Vizcarra "solicitó al jesuita Bernard Bergöend, familiarizado con la experiencia política belga, que elaborara un proyecto de organización política", ${ }^{20}$ y de ahí surgió el documento "Unión política social de los católicos mexicanos", presentado en 1910, el cual sería la base para la organización del PCN. De hecho, aun durante la breve existencia del partido, llegó a tener una participación considerable; por ejemplo, en el Congreso del estado de Jalisco, en el que el propio Palomar y Vizcarra fue diputado local, logrando impulsar algunas iniciativas de ley importantes.

Articuladas al PCN se encontraban dos organizaciones: la Liga Nacional de Estudiantes Católicos, a la que perteneció Jorge Prieto Laurens, futuro líder principal del Partido Nacional Cooperatista, y la Asociación Católica de la Juventud Mexicana (ACJM), creada en agosto de 1913, también bajo la guía ideológica del jesuita Bernard Bergöend, pero sobre la experiencia de la Asociación Juvenil Francesa. Unida en algún momento a las filas del Partido Católico Nacional, la ACJM tuvo tres ejes fundamentales en su orientación: piedad, estudio y acción, y se propuso luchar por la restauración del orden social cristiano:21 "Para la ACJM el problema político en México consistía en encontrar la forma de normalizar las leyes e instituciones políticas, de tal suerte que se lograra garantizar los derechos naturales y divinos, para llevar a la sociedad a cumplir con este último fin". ${ }^{22}$ Esta agrupación nació "como un instrumento efectivo para responder a la violencia anticlerical nacida con la Revolución", ${ }^{23}$ pero fue hasta 1918 cuando se formó su Comité Central, con René Capistrán Garza como su primer presidente laico.

Guerra, "Las elecciones", p. 256.

O’Dogherty, "Dios", p. 138.

Ibid., pp. 217-219.

Ibíd., p. 202. La influencia de Bergöend en la creación del PCN está también señalada en Dooley, Los cristeros, p. 14.

${ }_{21}$ Aspe, La formación, pp. 65-66.

22 Ibid., p. 69.

23 Dooley, Los cristeros, p. 14. Este autor subestima la participación de los católicos en el gobierno huertista, periodo en el que nace la ACJM, y sobredimensiona el nivel de la tensión 
Palomar y Capistrán fueron dos personajes centrales en la construcción de la red de organizaciones que en el transcurso de la década de 1920 pugnarían por combatir contra todas las medidas estatales que afectaban tanto a la Iglesia como a sus instituciones asociadas. Estas organizaciones fueron abundantes: los Caballeros de Colón, ${ }^{24}$ las Brigadas de Santa Juana de Arco, la Unión de Católicos Mexicanos, la Unión Nacional de Padres de Familia (UNPF), ${ }^{25}$ la Confederación Nacional Católica del Trabajo (CNCT), entre otras, son muestra de una actividad intensa por parte de los católicos, pero que cristalizó en pocos partidos cercanos a esta creencia. Con los arreglos de junio de 1929, que pusieron fin al conflicto religioso, tuvieron que reformular el conjunto de su política hacia el Estado.

\section{Liga Democrática. Tendencia Democrática}

Sin duda, la presencia de la organización política que articuló la campaña del general Pablo González hacia la presidencia de la República, en el marco de la sucesión presidencial de 1919-1920, puede parecer sorprendente dentro del tipo de agrupaciones que estoy analizando, pero quiero destacarla brevemente por dos razones: en primer lugar, por la presencia de Juan Sánchez Azcona en el Comité Ejecutivo de la Liga, y, en segundo lugar, por la recopilación que el Partido Reconstrucción Nacional llevó a cabo, en 1923, de los documentos relacionados con esta agrupación.

Así, el 27 de noviembre de 1919 se publicó la 'Plataforma Mínima' de la Liga Democrática, el documento en el cual el general Pablo González basaría su nominación, y se presentaba como el programa que los candidatos a diputados y senadores de la Liga Democrática deberían aceptar previamente a su postulación. Dicha plataforma la firmaba el presidente de la Convención de la Liga Democrática, Manuel Andrade Priego; el Comité Ejecutivo de la misma, Rafael Cepeda y, por la Comisión de Ordenamiento y Corrección de Estilo, Juan Sánchez Azcona. ${ }^{26}$

Sánchez Azcona fue un personaje que tuvo una participación muy activa en la política mexicana de la primera mitad del siglo $\mathrm{xx}$, pues, además de su viva

con el Carrancismo, al decir: "los meses durante los cuales Carranza consolidó su poder fueron una pesadilla para los católicos... fueron sometidos a una tremenda persecución" (Ibid, p. 15).

24 "Fascismo ayer. Hoy, la Liga de Defensa Religiosa. Y detrás de todo, siempre las siluetas tenebrosas de los 'Caballeros de Colón'”, El Sol de México, 25 de marzo de 1925.

25 "En la década de 1920, la UNPF no tuvo actividad muy intensa, y estuvo supeditada a los grupos católicos más antiguos: Caballeros de Colón, la Liga, la U y las Damas Católicas”. Pérez Méndez, "La Unión Nacional”, p. 176.

26 Mac Gregor Campuzano, Imaginar el futuro, p. 250. 
colaboración con el maderismo a principios de la década de 1910, aparecería después en un gran número de agrupaciones opositoras a los sonorenses (la primera de ellas fue, precisamente, la Liga Democrática). De hecho, coincidirá con algunos de los políticos de las organizaciones católicas, siempre en contra de los militares que habían depuesto y asesinado al presidente Carranza, de quien fue su último secretario de Relaciones Exteriores, lo que probablemente explique su militancia.

Por otra parte, el Partido de Reconstrucción Nacional organizó, en 1923, toda la documentación relacionada con la campaña de Pablo González a la presidencia, pues, al considerarse heredero de la Liga Democrática, integró documentos sobre su campaña y otros textos en los que el General presentaba una violenta diatriba en contra de los gobiernos de De la Huerta y de Obregón, a quienes consideraba bolcheviques: " $y$ en los que personajes como Calles, Eduardo Neri, José Vasconcelos, Luis Morones y otros 'apuntalarían el edificio bolchevique y pilotearían la nave por mares propicios para hacerla zozobrar". ${ }^{27}$ Tanto el tono desorbitado de la declaración como la profesión de fe antibolchevique se asemejan, ciertamente, a lo que algunos católicos, nacionales y extranjeros, propalarían durante toda la década en contra del régimen revolucionario (en algunos sectores católicos de Estados Unidos, la idea de Calles como dictador bolchevique era inamovible).

\section{Partido Nacional Cooperatista. Cooperativismo y Fraternidad}

Esta agrupación, surgida en 1917, tendría su época de auge y esplendor en el período de 1920 a 1923, cuando se convirtió en uno de los grandes pilares del gobierno obregonista, en su lucha por eliminar la influencia creciente tanto del Partido Liberal Constitucionalista en el Congreso, como de los gobiernos estatales al inicio de la década. ${ }^{28}$ No pretendo realizar aquí una síntesis de su actuación política durante los años de su mayor influencia, sino sólo buscar los nexos que estableció con los personajes y las organizaciones que aquí he presentado. Es cierto que algunos de los hombres más destacados del régimen revolucionario pasaron por sus filas (por ejemplo, Juan Manuel Álvarez del Castillo, Emilio Portes Gil, Roque González Garza y Luis L. León), pero también lo es que su líder indiscutible, Jorge Prieto Laurens, tenía un

27 Ibid., p. 258. De acuerdo con Ricardo Pérez Montfort, “el PRN, más que una organización ligada a la Iglesia católica, inició su errática presencia en el ambiente político mexicano, como un movimiento reaccionario que pretendía distanciarse del régimen de los sonorenses" (Pérez Montfort, "Tradición”, p. 303).

28 Una visión completa y detallada de esta agrupación se encuentra en Mac Gregor Campuzano, Imaginar el futuro, pp. 115-155. 
perfil católico y conservador, lo cual confirmó su militancia y dirigencia en importantes organizaciones anticomunistas de las décadas de 1940 y 1950.

Pese al discurso aparentemente radical y socializante que expresó el dirigente cooperatista cuando estuvo al frente del partido, Georgette José Valenzuela se pregunta si se puede caracterizar al Partido Cooperatista como católico; concluye que sí, pues, en cierta forma, es “el eslabón entre el Partido Católico Nacional de 1912 y el PAN fundado en 1939, aunque cabe señalar que no planteamos que sea el continuador de uno ni el antecedente directo del otro, como organización política". ${ }^{29}$ Aunque la segunda parte de esta afirmación es un poco contradictoria, quedémonos con la idea general. El discurso cooperativista que articuló la ideología del PNC campeaba en las organizaciones conservadoras y de derecha de la época, pues el sistema de cajas de ahorro y las cooperativas de préstamos (el sistema Raiffeisen, por ejemplo) se instrumentaron en algunos estados, con éxito regular. ${ }^{30}$

En el caso del partido, se presentaron pocas iniciativas de corte cooperativo ante el Congreso, que, en general, no fueron aprobadas. Este discurso contrastaba con otro francamente racista, el cual aparecía de manera recurrente en el órgano oficial del partido:

[...] es necesario buscar el mejoramiento racial de nuestros indios por medio de una bien organizada inmigración... es decir, la eliminación del indio por fusión directa con el blanco, inmigración que se debe reducir a miembros de la raza blanca, y de ninguna manera permitir la amarilla o negra, esta última por razones obvias de explicar. ${ }^{31}$

Así, una trayectoria personal de origen católica (decíamos que Prieto Laurens provenía de las filas de la Liga de Estudiantes Católica y del Centro de Estudiantes Católicos), un programa que se ajustaba — en general - al de las organizaciones de derecha de la época, la participación en un levantamiento armado que fue tildado como reaccionario por el gobierno y algunos analistas, ${ }^{32}$ y un final en la militancia anticomunista por su dirigente son asuntos que nos acercan más al conservadurismo que al carácter progresista de buena parte del conjunto político de esos años.

29 José Valenzuela, “Entre el poder”, p. 214.

$30 \quad$ Al respecto, véase Barbosa Guzmán, "La cooperativa".

31 Gabino A. Palma, "Nuestra crisis espiritual”, en Cooperación, Tomo I, núm. 1, octubre de 1922.

32 Con lo que, de alguna manera, Georgette José Valenzuela coincide al enfatizar el carácter "marcadamente antiagrarista" de esta rebelión; Ramos Pedrueza afirmó, años antes, que la asonada de 1923 tuvo "una estructura clasista contrarrevolucionaria". Ramos Pedrueza, La lucha, p. 281. 
Pero el puente del Cooperatista, en todo caso, no debe establecerse con el Partido de Acción Nacional, sino con otro más próximo, con el cual se empalmó a finales de 1923: la Liga Política Nacional y su candidato Ángel Flores, lo que estudiaré más adelante.

\section{Partido Nacional Republicano. Patria y Libertad}

Pese a sus esfuerzos por no aparecer como tales, la prensa puso como su encabezado principal la siguiente leyenda: "Los católicos, organizados en partido, entran a la lucha electoral" ${ }^{33} \mathrm{El}$ contenido de la nota enfatizaba este hecho:

El Partido Católico, que tanto auge tuvo durante el gobierno usurpador de Victoriano Huerta, nuevamente y con el nombre de Partido Nacional Republicano, vuelve a la palestra electoral, con objeto de elegir, en gran convención, [a] su candidato a la presidencia de la República.

El público se ha dado cuenta de que junto a los avisos que se fijan en los propileos de los templos católicos, figura el manifiesto del Partido Nacional Republicano, suscrito por el licenciado Rafael Ceniceros Villarreal, que funge de presidente, y por el señor Manuel León, que figura como secretario. ${ }^{34}$

La crítica abierta al marco institucional que derivaba de la Constitución de 1917 fue uno de los aspectos más característicos de este partido y, más tarde, de su candidato presidencial.

El Centro General del Partido Nacional Republicano —su órgano directivo - quedó constituido de la siguiente manera: presidente, Rafael Ceniceros y Villarreal; primer vicepresidente, Carlos Vargas Galeana; segundo vicepresidente, René Capistrán Garza; secretario, Mauricio Villalobos; primer prosecretario, Eduardo Beltrán Mendoza; segundo prosecretario, Carlos T. Maceyra; tesorero, Luis M. Flores; vocales propietarios, Rodolfo T. Villalpando, Andrés Bermejillo, Luis Armas Farías, Salvador Sánchez Barquera, Manuel León y Enrique Ricoy, y vocales suplentes, Agustín Álvarez, Alfredo Landero, Estanislao Suárez, Luis Bustos, J. Jesús Román e Isauro López.

Los nombres de los antiguos miembros del Partido Católico, de los acejotaemeros, de los Caballeros de Colón y de otros miembros de los grupos católicos más preclaros se vinculan en esta agrupación de manera estrecha. A partir de 1925, prácticamente todos eran integrantes fundamentales de la Liga Nacional de Defensa de la Libertad Religiosa. Junto a ellos, según Alfonso Taracena, aparece Diego Arenas Guzmán como miembro de la Mesa Directiva

34 Ibid. Curiosa mención al vínculo entre el Partido Católico y el gobierno de Huerta, pues, como ya vimos, fue en este período cuando desapareció. 
y, según la prensa de la época, como delegado a la Convención que postuló a su candidato presidencial.

Al propio candidato que provino de esta Convención del 19 de julio, Alfredo Robles Domínguez, se le asociaba con el Partido Católico y los Caballeros de Colón, ${ }^{35}$ a pesar de que todos reconocían sus antecedentes, primero, como antiguo maderista $\mathrm{y}$, después, como enviado del gobierno de Carranza en Washington. La campaña presidencial de Robles Domínguez nunca tuvo posibilidad de despegar plenamente, ante la corriente poderosa e imparable del obregonismo, la cual alcanzó un triunfo arrollador en los comicios de septiembre de 1920 .

Un dato curioso, como colofón a este proceso, fue la aprehensión de Robles Domínguez, en 1921, por el delito de rebelión:

Se iniciaban las suntuosas fiestas de la Consumación de la Independencia Mexicana, cuando el sábado 3 de septiembre de 1921, a las 12 horas y treinta minutos de la tarde, arriban por la estación colonia en el tren ordinario de Laredo, el ingeniero Alfredo Robles Domínguez y los señores Diego Arenas Guzmán, Carlos Díaz de León, licenciado Pedro González, general Aurelio Leal Treviño, Manuel García y Luciano Cortina, quienes venían conducidos por un grupo de soldados del $4^{\circ}$. Batallón y varios celadores del resguardo de Nuevo Laredo al mando del primer comandante, señor José Anaya Terán. ${ }^{36}$

La aprehensión y posterior liberación de Robles Domínguez y compañeros han sido ignoradas por la historiografía política. ${ }^{37}$ Pero el vínculo quedó esclarecido: Robles Domínguez y otro distinguido maderista como Diego Arenas Guzmán compartían la misma plataforma en el Partido Nacional Republicano, con lo más granado de la derecha mexicana (Palomar y Vizcarra, Capistrán, Luis G. Bustos, Rafael Ceniceros), en una aventura electoral que no tenía visos de un éxito real. En todo caso, nos informa acerca de la necesidad de estos políticos de aparecer en el escenario político nacional y crear - $\mathrm{O}$ relacionarse con- cualquier agrupación que le significara al Estado una oposición activa. amplia sobre la actuación de este partido.

36 Casasola, 1960, p. 1549.

37 El 4 de septiembre de 1921, El Demócrata informó sobre la captura de Robles Domínguez, autoproclamado como "presidente legal" del país, el cual argumentó que fue víctima de un engaño, pues, estando en Estados Unidos, se le informó de una supuesta reunión programada con Álvaro Obregón, pero que, al cruzar la frontera, se le capturó. Fue liberado diez días después, junto a Diego Arenas Guzmán. 


\section{Partido Fascista Mexicano. Orden y Justicia}

La actividad de esta organización ha sido estudiada ampliamente en otros textos, ${ }^{38}$ por lo que aquí sólo cabe ofrecer una semblanza, muy general, que destaque los vínculos que estoy analizando.

El Partido Fascista Mexicano se creó en diciembre de 1922, y presentó una serie de planteamientos programáticos en un "Manifiesto del Partido Fascista Mexicano a la Nación”, fechado en diciembre de 1922, así como los "Principios fundamentales del Fascismo Nacional Mexicano", publicados en México el 3 de abril de $1923 .{ }^{39}$ De estos documentos, destaca su preocupación por lo que consideran un avance artificial del bolchevismo importado de Rusia, y llaman a trabajar:

[...] contra los abusos, contra esas dictaduras, contra la injustificada y absurda opresión en que las clases sociales se encuentran, contra los radicalismos de nuestra legislación y las fanáticas intolerancias ultra-jacobinas que han venido a convertir en añicos uno de los más sagrados derechos del hombre, como es el relativo a adoptar y practicar la religión o credo que más les plazca, contra las teorías disolventes que llegan hasta el extremo de atacar y pretender destruir los vínculos de la nacionalidad mexicana, contra todos esos desmanes el Fascismo Mexicano está resuelto a combatir con perseverante energía. ${ }^{40}$

Algunos de sus "Principios fundamentales" mostraban plena congruencia con los que también reclamaban las organizaciones de derecha antes mencionadas. Por ejemplo, y aquí podemos ver el parecido con las demandas que ya presentaba el Partido Católico a principios de siglo, el fascismo mexicano exigía la renovación "de las leyes y de las reformas institucionales sociales, en tanto no garanticen los derechos naturales para este fin". De hecho, abogaban por algo que, de cierta forma, ya estaba contemplado en los mecanismos de representación adoptados por el propio Congreso: "se establecerá el derecho de iniciar leyes ante el poder legislativo y el de pedir la derogación o reformas de las existentes". ${ }^{41} \mathrm{Al}$ mismo tiempo, se proponían "exigir [el cumplimiento de] los principios del sufragio efectivo y no reelección, restablecidos por el

38 Básicamente, lo han realizado Mac Gregor Campuzano, Imaginar el futuro, pp. 309-325; José Valenzuela, El relevo, pp. 60-75, y Braderman, A study, pp. 212-215. En fecha reciente, ha sido estudiado por Pérez Montfort, “Tradición”, pp. 296-302. Un análisis detallado de estos documentos se encuentra en Mac Gregor Campuzano, Imaginar el futuro, pp. 313-317.

39 Un análisis detallado de estos documentos se encuentra en Mac Gregor Campuzano, Imaginar el futuro, pp. 313-317.

40 "Manifiesto del Partido Fascista a la Nación", NAW/Department of State/Reel 92. 812.00. Fascist Movement, diciembre de 1922, p. 2. Cursivas mías.

41 "Principios fundamentales del Fascismo Nacional Mexicano", NAW/Department of State/ Reel 92. 812.00. Fascist Movement, abril de 1923, p. 1. 
movimiento revolucionario de 1910, pero extendiéndolos a todos los cargos de representación popular". ${ }^{42}$

El representante principal de esta organización fue el ingeniero Gustavo Sáenz de Sicilia, quien, además de dirigirla, fue el miembro más destacado de la Comisión Organizadora, por las declaraciones periódicas que realizaba. ${ }^{43}$

Con miras a definir la relación que esta agrupación estableció con el resto de las organizaciones de derecha en ese período (aunque su denominación y credo, en sí mismos, ya la catalogaban así), habría que destacar la atención otorgada a la figura de Guillermo Pous. Prácticamente, la única mención que se hace de Pous, como personaje vinculado con el PFM, aparece en un informe de la inteligencia militar estadounidense, cuando se señalaba —al caracterizar al Partido Fascista - que "el Sr. Guillermo Pous fue hecho cabeza del partido en abril de 1923", y, cuando se refería a la labor del Sindicato Nacional de Agricultores, que Pous había sido director del SNA, al renunciar a la dirección del Partido Fascista. ${ }^{44}$ Esto es importante, porque su nombre no aparece entre los firmantes — por la Comisión Organizadora - del Manifiesto de 1922, como tampoco en los debates que la presencia del fascismo suscitó en el Congreso.

De haber sido Pous un integrante del PFM, tendríamos un nuevo enlace con la que sería la organización política que aglutinó a todas las anteriores, y que, en cierta forma, se convierte en el puente entre toda la tradición política católica anterior, y la que le seguiría. Este es el caso de la Liga Política Nacional.

\section{Liga Política Nacional. Libertad y Garantias}

El 6 de mayo de 1924, Ignacio Gastelum, Jorge Morfín y Delorme y Evaristo Paredes, presidente, secretario y prosecretario, respectivamente, de la Liga Política Nacional, comunicaron a la Secretaría de Gobernación que el 25 de marzo se había realizado la asamblea constitutiva de dicha organización, por lo que solicitaban su registro. Al mismo tiempo, pedían que se diera por registrada, "con la Liga Política Nacional, la candidatura del C. Gral. Ángel Flores, para la Presidencia de la República en el próximo período". ${ }^{45}$ El registro se les otorgó el 9 de mayo, bajo la condicionante de entregar la documentación faltante.

El acta protocolizada, que incluía la documentación presentada, señalaba que el 5 de septiembre de 1923 se había reunido un grupo de ciudadanos con

$42 \quad$ Ibid.

43 De acuerdo con lo investigado por Pérez Montfort, Sáenz de Sicilia era gerente de la Compañía Nacional Productora de Películas, "y había realizado un par de cintas a principios de los años veinte de clara 'filiación racista"”. Pérez Montfort, "Tradición”, p. 298.

44 U.S. Military Intelligence reports: Mexico, 1919-1941. Reel I, 0549, G-2. Subject 3700, No. 177, Political Parties. Mexico, April 23, 1925.

45 AGN/DGG/E.2.00.9.6, Vol. 30, Exp. 42. México, D.F. 3 de mayo de 1924. Ignacio Gastelum a Secretaría de Gobernación. 
el fin de formar un partido político, la Liga Política Nacional. Inmediatamente, se destacaba su programa:

1. Gobierno nacional. 2. Respeto a las instituciones de la familia y de la propiedad. 3. Solución del problema agrario sobre bases de justicia y equidad. Creación de la pequeña propiedad asequible a todos. 4. Armonía entre el capital y el trabajo. Legislación protectora del trabajador. 5. Protección al comercio y a la industria, desarrollo de la marina nacional. Garantías a la inversión de capital. 6. Moralización de la administración pública y del mecanismo judicial. Creación del servicio civil, garantizando la estabilidad y recompensas del empleado público y haciendo efectivas las Leyes de responsabilidad para los funcionarios públicos. 7. Dignificación del ejército. 8. Sufragio efectivo y no reelección. 9. Libertad para todos: de conciencia, de enseñanza, de asociación y de trabajo. 10. Igualdad para todos ante la ley. ${ }^{46}$

De hecho, a principios de octubre de 1923 ya se mencionaba abiertamente que el candidato de la Liga Política Nacional era el general Ángel Flores. ${ }^{47}$

Poco tiempo después de la reunión para la creación del partido, el Departamento Confidencial de la Secretaría de Gobernación informaba sobre la nueva agrupación. El 11 de octubre, el agente José Soto comunicaba al general Paulino Navarro, jefe del Departamento, que "esta agrupación recientemente formada cuenta a la fecha con un número de socios reducido, integrándola en su mayoría elemento católico y burgués" ${ }^{48} \mathrm{El}$ informe continuaba de la siguiente manera:

La mencionada corporación política obra y marcha de común acuerdo con el Sindicato Nacional de Agricultores, que tiene sus oficinas generales en la Av. Fco. I. Madero No. 2. Esta institución ya con anterioridad ha estado efectuando trabajos en todo el país sindicalizando a todos los agricultores de la República teniendo ramificaciones con más esfera de acción y más bien organizadas en los estados de Jalisco, México, Morelos, Puebla, Oaxaca, Querétaro, Guanajuato, Michoacán, Tlaxcala, Aguascalientes y Sinaloa, por esta circunstancia dicha Liga Política Nacional, puede tomar fuerza política en el país. ${ }^{49}$

Es importante destacar esta distinción entre el Sindicato de Agricultores y la Liga Política, pues, con frecuencia, la candidatura de Ángel Flores ha sido

46 Ibid., México, D.F. 26 de abril de 1924. Protocolización del acta constitutiva y programa de gobierno de la Liga Política Nacional. Cursivas mías.

47 CDEHM Carso, fondo DCXXI 10.941.2. México, 8 de octubre de 1923. J. Espinosa a Richard Williams.

48 AGN/DIPS/311(PE)"23" BIS, Vol. 2046-A, Exp. 2, f. 3. México, D.F. 11 de octubre de 1923. José Soto a Jefe de Departamento Confidencial. Cursivas mías.

49 Ibíd. 
confundida por la historiografía como proveniente del Sindicato, cuando la postulación legal y las boletas electorales aparecieron bajo el distintivo de la Liga. Incluso, algunos autores hablan de la LPN como "brazo político" del Sindicato, aunque ciertamente no eran iguales..$^{50}$ En julio, los integrantes del Partido Nacional Republicano - de tendencia católica, al que he estudiado líneas atrás - se unieron al esfuerzo electoral de los floristas. ${ }^{51}$

Desde la perspectiva de este ensayo, interesa destacar quiénes eran los principales actores y dirigentes de esta organización político electoral. Para el momento de su creación, la Liga contaba con la siguiente Junta Directiva: presidente, Ignacio I. Gastelum; primer vicepresidente, Francisco Lagos Cházaro; segundo vicepresidente, Salvador Domínguez; secretario, Jorge Morfín y Delorme; prosecretario, Evaristo Paredes; tesorero, Manuel Amieva, y vocales, René Capistrán Garza, Rafael Sosa, Miguel Palomar y Vizcarra, Emeterio Martínez de la Garza, José Ramos, Miguel Bernard, Ezequiel Rosales, Juan Sánchez Azcona, Guillermo Pous, Moisés García, Mariano García Sepúlveda y Bartolomé Ontiveros. ${ }^{52}$ De nuevo, encontramos a una buena parte de los nombres que habían aparecido en las organizaciones antes mencionadas, agrupados alrededor de la candidatura del sinaloense, la cual - como es natural - tenía muy pocas posibilidades de triunfar frente a la avalancha callista que se manifestaba en todos los rincones del país. ${ }^{53}$

Como sabemos, las campañas electorales de 1923, rumbo a las elecciones de julio del año siguiente, se vieron interrumpidas por la rebelión delahuertista que estalló en diciembre de 1923. Naturalmente, este levantamiento se convirtió - por su magnitud - en la preocupación principal del régimen, y, pese a que en general la situación política ya estaba controlada hacia abril de 1924, la identificación de todos aquéllos que hubieran estado imbricados o que simpatizaran con la rebelión fue seguida con atención por el gobierno. De ahí que, el 26 de junio de 1924, una vez controlado el levantamiento y a pocos días de la elección, un informe del Departamento Confidencial diera cuenta de los perfiles de algunos candidatos y senadores por el Distrito Federal. Destaco aquí algunos de los nombres más conocidos:

50 Lo cual no deja de recordar a la similitud entre la CROM y el Partido Laborista Mexicano; este último, como brazo político de la organización social. José Valadés menciona que el Sindicato de Agricultores se formó por un grupo de agricultores lastimados por la Ley Agraria. Valadés, Historia, p. 315.

51 José Valenzuela, La campaña, p. 239.

52 AGN/DGG/E.2.00.9.6 Vol. 30, Exp. 42. México, D.F. 26 de abril de 1924. Protocolización del acta constitutiva y programa de gobierno de la Liga Política Nacional, fs. 1-2.

53 Un análisis general de este proceso, visto desde la votación en algunos distritos electorales del país, se encuentra en Mac Gregor Campuzano, "Constitución”, en donde aparecen las candidaturas de algunos de los personajes aquí mencionados. 
Guillermo Pous. Es un prominente miembro del Sindicato Nacional de Agricultores. Aunque no ha tomado participación directa en bando político alguno se ha distinguido por su labor de obstrucción al Gobierno atacando por medio de la prensa casi todas las disposiciones sobre la cuestión agraria y de Aguas Libres. Hoy es 'florista' y está apoyado por el Partido Nacional Pacifista.

Juan Sánchez Azcona. Conocido elemento revolucionario. Fue senador hasta 1922. Amigo personal del presidente Obregón, aun estando contra 'su política' se ha significado por su mesura y ecuanimidad para atacarlo. Fue Secretario de Relaciones, por poco tiempo, al triunfo del movimiento de 1920. Fue uno de los jefes de propaganda de los candidatos presidenciales Raúl Madero y Carlos B. Zetina. Ahora se significa dentro del grupo 'florista'. Es postulado por la Unión Revolucionaria Nacional y la Unión Patriótica Electoral ‘Ángel Flores’. 54

Asimismo, el agente confidencial ofrecía información general sobre los candidatos a diputados — por la capital del país — que este grupo de políticos "floristas" presentaba. Sólo mencionaré a uno:

René Capistrán Garza. Es el que maneja a los miembros de la Asociación de Jóvenes Católicos Mexicanos. Se ha distinguido por sus alardes de entereza al atacar al Gobierno del Gral. Obregón. Siempre se ha dicho un 'lugarteniente' del Arzobispo de México. Fue regidor cooperatista en 1920, abandonando su puesto al triunfo del movimiento de Agua Prieta. Enemigo enconado del Gral. Calles. ${ }^{55}$

De esta misma forma, el gobierno realizó el seguimiento de docenas de individuos, tanto leales como combatientes al régimen, particularmente en esa crucial coyuntura del levantamiento delahuertista.

La actitud del propio general Ángel Flores frente a la rebelión fue de neutralidad, ${ }^{56}$ la cual — según Georgette José Valenzuela - aparentemente terminó cuando, “impulsado por Pous, Gastelum, Capistrán Garza y otros fijaron una fecha de un levantamiento en contra del gobierno el $1^{\circ}$ de noviembre de 1924". 57

Es probable que esto haya impulsado a Ángel Flores a lanzar un "Manifiesto a sus partidarios y a la Nación Mexicana", el $1^{\circ}$ de diciembre de 1924, en Culiacán, Sinaloa, en el que llamaba a empuñar las armas "para derrocar al tirano impuesto". ${ }^{58}$ Después de presentar su versión acerca del resultado

54 AGN/DIPS/331(5.1)-1. Vol. 166, Exp. 2, f. 71. México, D.F. 26 de junio de 1924. Agente M. a Jefe de Departamento Confidencial.

Ibid.

José Valenzuela, “Ángel Flores”, p. 210.

Ibid., p. 223.

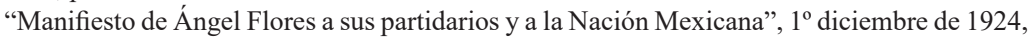
Culiacán, Sinaloa, en Ulloa y Hernández, Planes, Libro 8, pp. 191-192. 
electoral de julio (persecución, asesinatos, encarcelamientos, robos de ánforas), así como de dar cuenta de que la imposición siempre estuvo presente, expresó:

En estas condiciones, en atención a que mis partidarios no han desmayado volviendo sus ojos hacia mí, pidiendo que no los deje ni los abandone, haciéndome ver que Plutarco Elías Calles quiere hacer de la Nación Mexicana la sucursal de la Rusia Soviet, que al tener Calles el mando supremo cometerá mil atentados, convirtiendo los templos de la Religión Católica que es la que profesa la inmensa mayoría de los mexicanos en mezquitas y cuarteles, substituyendo nuestro Ejército en filibusteros turcos, rusos y árabes, de los que ya han llegado en grandes caravanas a la ciudad de México, ofreciendo repartirles terrenos con perjuicio de nuestros nacionales y, en suma, comprendiendo que al escalar el poder Plutarco Elías Calles, será la ruina y la desgracia de mi querida Patria, digna de mejor suerte, aun a costa de mi vida he decidido no abandonar a mis partidarios. ${ }^{59}$

A partir de lo anterior, desconocía a Calles como presidente, a los poderes de la Unión y a las demás autoridades de la República. Este levantamiento no trastocó ni el orden ni la toma de posesión de Calles como presidente constitucional, el $1^{\circ}$ de diciembre. Ángel Flores falleció en marzo de 1926 (posiblemente fue asesinado). Aunque esto no ha sido estudiado a profundidad, debemos considerar que obtuvo un gran número de votos en julio de 1924; ganó la elección en su estado natal, Sinaloa, y había intentado organizar un movimiento subversivo a finales de ese año. ${ }^{60}$ Quizá la política de la época, caracterizada por Jesús Silva Herzog como aquella en la que "la Revolución devoró a sus hijos", se puso nuevamente en acción.

\section{Liga Nacional de Defensa de la Libertad Religiosa. Dios y mi Derecho}

Son numerosos los trabajos que han estudiado la génesis y el desarrollo de esta organización católica, la cual, sin ser propiamente un partido político, buscó derrocar al Estado y establecer un nuevo sistema de dominio, que excluía con claridad los principios más avanzados del texto constitucional. ${ }^{61}$

60 Cuando Georgette José Valenzuela se pregunta si Ángel Flores fue un candidato reaccionario, responde que lo fue "de la oligarquía católica terrateniente y comercial, aliada a los revolucionarios desplazados, que había sido derrotada, pero no aniquilada, a la cual se le había arrebatado el poder político, más no el económico y que, ante los hechos consumados, comenzó a buscar el camino de la reconciliación; primero, mediante las elecciones de 1924, después, mediante la guerra con la rebelión cristera, y posteriormente, por medio del compadrazgo económico y el maridaje político con los revolucionarios triunfantes". José Valenzuela, "Ángel Flores", p. 224.

61 Mencionaré únicamente los trabajos clásicos de Dooley, 1976, 214 pp. Los cristeros; Olivera Sedano, Aspectos; Meyer, La cristiada 1 y 2, y García Ugarte, "Los católicos". En un artículo 
Formada como una respuesta a la provocación que significó el intento de establecer una Iglesia católica mexicana: la Iglesia cismática del patriarca Pérez, en el Templo de la Soledad, en febrero de 1925, la Liga Nacional para la Defensa de la Religión se formó el 14 de marzo de 1925, y presentó su programa y contenido de manera general, ante la prensa, el 21 del mismo mes.

Entre otros de los elementos que de inmediato fueron considerados como subversivos por el gobierno - por medio del secretario de Gobernación, Gilberto Valenzuela-, se encontraban las siguientes afirmaciones:

Se nos ha llamado al combate, se nos obliga a ello con persecuciones injustas y tiránicas; lamentamos la guerra, pero nuestra dignidad ultrajada y nuestra fe perseguida nos obliga[n] a acudir para la defensa, al mismo terreno en que se desarrolla el ataque. Esta es la única manera de que tengamos libertad y de que se nos haga justicia; y para esto precisamente se funda la Liga Nacional de Defensa Religiosa. ${ }^{62}$

Dicho manifiesto continuaba diciendo:

La Liga es una asociación legal, de carácter cívico, que tiene por fin conquistar la libertad religiosa y todas las libertades que se deriven de ella en el orden social o económico, por los medios adecuados que las circunstancias le irán imponiendo. La Liga quiere ser una asociación de los verdaderos católicos mexicanos, cansados ya de tantos atropellos en contra de su religión, del orden social y de sus derechos cívicos tan cínicamente burlados en los comicios [...]

El fin de la Liga es, pues, detener al enemigo y reconquistar la libertad religiosa y las demás libertades que se derivan de ella. Tiene un programa que no es un grito de guerra ni una exigencia fuera de propósito; es solo una síntesis de justas y debidas reivindicaciones a que tienen derecho los mexicanos para poder vivir como católicos, y que nadie en una república democrática, puede poner en tela de juicio. ${ }^{63}$

El programa general se reducía a los siguientes puntos:

$1^{\circ}$. Libertad plena de enseñanza.

$2^{\circ}$. Derecho común para los ciudadanos católicos.

$3^{\circ}$. Derecho común para la Iglesia.

$4^{\circ}$. Derecho común para los trabajadores católicos.

reciente, César E. Valdez utiliza el expediente de la Dirección de Investigaciones Políticas y Sociales que aquí analizo, pero, más que para el estudio de la LNDLR misma, para conocer los mecanismos a través de los cuales la Secretaría de Gobernación seguía a sus opositores. Valdez, "La Liga".

62 El Universal, 22 de marzo de 1925.

63 Ibid. 
Como ya mencioné, el gobierno lo consideró subversivo y, al día siguiente de la aparición del manifiesto en la prensa, de inmediato mandó a los agentes del Departamento Confidencial a realizar un seguimiento estrecho de esta agrupación.

En un informe fechado el 7 de abril, el agente 18 comentaba el mismo documento, y afirmaba que la Liga estaba integrada por miembros de la Orden de Caballeros de Colón y de la Asociación de Jóvenes Católicos; que la Asociación de Damas Católicas no era ajena a la Liga, y que, "de manera secreta, los curas católicos pertenecen a esta organización y se dedican con toda ostentación a llevar a cabo su propaganda". ${ }^{64}$ Después de transcribir largos párrafos del documento aludido, concluía lo siguiente:

La Liga, al estar en pugna sus fines con los de la Constitución y al pedir la reforma de ésta en sus artículos que trata la cuestión religiosa está haciendo labor en contra de las instituciones establecidas y por lo cual debe considerarse su labor perfectamente sediciosa. Los curas en los púlpitos y los propagandistas en reuniones públicas y privadas están llevando a cabo una fuerte acción en favor de la iglesia y en contra del gobierno, presentando a éste como el fomentador de los últimos disturbios de separatismo que encabeza el cura Pérez. Entre los católicos existe ya esa creencia embuída [sic] por la propaganda de la Liga, para buscar la animadversión contra el actual orden de cosas y promover así dificultades que vengan a alterar el orden y la paz. ${ }^{65}$

Los nombres que firman el manifiesto de la Liga, y que el agente transcribe, eran los siguientes: Rafael Ceniceros y Villarreal, José Esquivel Alfaro, Miguel Palomar y Vizcarra, Carlos F. de Landero, René Capistrán Garza, Juan Laine, Enrique Toroella, Rafael Capetillo, Manuel de la Peza, Manuel del Valle, Mariano Laris, Ramón y Luis Ruiz y Rueda, Edelmiro Traslosheros, Fernando Silva y Francisco Palencia Llerena.

La conexión entre varios de los nombres aquí referidos ya ha aparecido en las agrupaciones presentadas anteriormente, y cierra, de alguna manera, la red de relaciones que se habían venido tejiendo desde la fundación del Partido Católico Nacional.

Jean Meyer menciona que la Liga daba muestras de un hispanismo y un nacionalismo fervientes, y que "se atribuía como héroes protectores a Iturbide, Lucas Alamán, Miramón y Mejía, y execraba a los liberales mexicanos, a los masones y a los protestantes yanquis, tres cabezas de una sola hidra que trata de devorar a México: el imperialismo norteamericano". ${ }^{66}$

65 Ibid., f. 24.

66 Meyer, La cristiada 1, p. 65. En plena guerra, en 1927, un autor cercano a las posiciones 
El mismo Meyer realiza una síntesis amplia del desarrollo del conflicto, a partir de 1926. ${ }^{67}$ Narra las declaraciones de Monseñor Mora y del Río, publicadas por El Universal el 4 de febrero de 1926, en las que se anunciaba que la Iglesia no aceptaría el contenido anticlerical de varios artículos constitucionales; las medidas antirreligiosas que se tomaron en diversos gobiernos de los estados, entre marzo y mayo, en respuesta a un llamado del gobierno federal; el decreto emitido por Calles, en julio, que reformaba el Código Penal, particularmente en lo que se refería al artículo 130 (con la Ley Calles, "lo que Calles sí había determinado era hacer cumplir los artículos de la Constitución que se referían al culto y sus ministros"); tanto la suspensión del culto religioso, a finales de julio, como el boicot económico a los que llamó la Liga; el debate público que se llevó a cabo, a principios de agosto, en el Teatro Iris, entre católicos y algunos miembros del régimen revolucionario; la entrevista entre Calles y Monseñor Díaz y Monseñor Ruiz y Flores, en agosto, en donde el sonorense les sugirió presentar ante el Congreso sus demandas de modificaciones constitucionales ("las Cámaras... o las armas"), y, finalmente, la preparación, a finales de septiembre, de la acción armada por parte de la Liga, es decir, el inicio de la Guerra Cristera.

El borrador de un memorándum de la Procuraduría General de la República daba cuenta, a principios de 1927, de la forma en la que se había desarrollado el conflicto religioso "provocado por la Liga Nacional Defensora de la Libertad Religiosa", así como del proceso de detención de varios de sus dirigentes o simpatizantes y del cateo a casas y templos que se presumían cercanos a la misma, desde julio de 1926. Llama la atención el dato de que, "con fecha [de] 6 de octubre [de 1926] fue internado a la prisión Militar de Santiago Diego Arenas Guzmán, Director del periódico 'La Controversia' por hacer propaganda religiosa, habiendo sido consignado a las autoridades competentes" ${ }^{68}$ Activo participante en múltiples agrupaciones oposicionistas en el transcurso de la década, al maderista difícilmente lo hubiéramos vinculado con los integrantes de la Liga, pese a sus diversas convergencias en la época del Partido Nacional Republicano; pero aquí apareció, y fue encarcelado.

del gobierno escribía: "aprovechando las dificultades que le habían presentado al gobierno mexicano, con motivo de la legislación petrolera, comenzó el clero a instigar en el país vecino, desarrollando una verdadera labor de traición, por medio de esa especie de mafia yankee que se ha propagado en nuestro país con el nombre de Caballeros de Colón. Estos, de acuerdo con el alto clero mexicano, creyeron fácil derribar al gobierno, apoyados con el dinero de los petroleros americanos para satisfacer luego sus ansias de mando estableciendo la teocracia, que ha sido su bello ideal”. Toro, La Iglesia, p. 384.

67 Meyer, La cristiada 2, pp. 220-328.

68 AGN/DIPS, 313.1-175, Tomo II. Vol. 228. Exp. 33, fs. 10-11. México D.F. s.f. Procuraduría General de la República. Memorándum relativo al Asunto Religioso. 
Los arreglos firmados en junio de 1929 pusieron fin al conflicto armado, y, si bien la tensión en las relaciones entre el Estado y la Iglesia permaneció latente durante varios meses, la guerra apaciguó y la Liga prácticamente desapareció del panorama político nacional. De hecho, pocos meses después de firmados los acuerdos, el delegado apostólico Leopoldo Ruiz — arzobispo de Morelia - se dirigió a uno de los dirigentes de la Liga, sugiriéndole que, "terminado el conflicto religioso, se dedicaran a la acción cívica o social católica, subordinados directamente [...] al Ilmo. Sr. Díaz, presidente de la Acción Católica de la República”. El necesario deslinde respecto a la jerarquía eclesiástica era enfáticamente enunciado:

Resumiendo; Cambien de nombre, dedíquense a la acción cívica, y si entran en política, háganlo por medio de elementos independientes de los que hasta hoy formaron parte de la L.N.D.L.R. suspendan toda actividad relacionada con el Referendum, queden por lo mismo independientes de la Iglesia, siguiendo como buenos católicos las normas generales del Catolicismo. ${ }^{69}$

En la década siguiente asistiremos a la creación y expansión de un amplio número de agrupaciones conservadoras, de las cuales el PAN será la más sobresaliente.

\section{Partido Nacional Antirreleccionista. Sufragio efectivo, No reelección}

Sin que podamos considerarlo como un partido cercano a los principios por los que habían desplegado su actividad varias de las organizaciones antes mencionadas, el Partido Nacional Antirreleccionista se constituyó el 21 de abril de 1927, en plena Guerra Cristera, con el claro propósito de combatir a la que ya aparecía como la candidatura a vencer: la del expresidente Álvaro Obregón.

Dos razones, muy generales, justifican la inclusión del partido en este listado. Por un lado, por la presencia de quien fuera un inquieto político maderista - pero también, con anterioridad, un integrante del Nacional Republicano y de la Liga Política Nacional—, Juan Sánchez Azcona, quien fue miembro de la dirigencia del partido y desempeñó un papel destacado en la Convención celebrada del 20 al 22 de junio de 1927.

Sánchez Azcona fue quien realizó la síntesis sobre el programa de gobierno del partido, destacando la democratización del poder, por el que se luchará para que 'el Ejecutivo no se abrogue facultades que corresponden al judicial'. Llamaban, además, a la democratización del ejército, reformando las actuales 
leyes militares, y dando a entender que se trataría de facultar a sus miembros para tomar parte en las luchas políticas, porque lo contrario es la causa 'de que cada soldado mexicano crea que lleva en su mochila un girón de la banda tricolor presidencial' ${ }^{70}$

Al finalizar la Convención, el partido postuló al general Arnulfo R. Gómez como candidato a la presidencia de la República, en un proceso en el que como es sabido - ninguno de los candidatos opositores llegó a las urnas en julio de 1928.

Por otro lado, en este ensayo también se ha incluido a esta organización debido a la observación que realizó un agente del Departamento Confidencial acerca de los trabajos que se llevaron a cabo en la Convención, después del análisis que elaboró en el transcurso del evento:

[...] vengo al convencimiento [de] que los componentes de esta Convención, en su gran mayoría fueron miembros del 'Partido Cooperatista Nacional', y algunos de estos fueron partidarios del movimiento revolucionario de 1923. La dirección intelectual de estos trabajos, se encuentra a cargo de reconocidos miembros que fueron del 'Partido Liberal Constitucionalista', y que por su práctica política dominaron en el criterio político de la Convención. ${ }^{71}$

Si bien es cierto que la propuesta política principal de esta agrupación se articulaba alrededor de la no reelección y el respeto al sufragio, y que no tenía ningún interés por la crítica a cualquiera de los artículos originales de la Constitución (particularmente los de contenido educativo o religioso), la presencia de Sánchez Azcona, así como el perfil político que el agente trazó de los participantes en la Convención, como antiguos cooperatistas,${ }^{72}$ permitieron crear un nuevo vínculo con la red de personajes y organizaciones de perfil conservador, que aquí he expuesto.

\section{CONSIDERACIONES FINALES}

Hemos visto una serie de partidos y organizaciones que en el transcurso de la década de 1920 se movilizaron para combatir tanto al régimen emanado de la Revolución como a la Constitución de 1917. Éstos fueron las compañías extranjeras y los empresarios nacionales, contra los artículos 27 y 123; los hacendados y latifundistas, contra el artículo 27; los padres de familia, contra

70 Mac Gregor Campuzano, Imaginar el futuro, p. 425.

71 AGN/DIPS, 311 (PE)"28", Tomo II, Vol. 2046-B, Exp. 2. México, D.F. 22 de junio de 1927. Agente No. 19 a Jefe de Oficina, f. 64. Cursivas mías.

72 Recordemos que varios de ellos habían pertenecido a organizaciones católicas de principios de siglo. 
el $3^{\circ}$, y la Iglesia, contra los artículos $3^{\circ}$, 24, 27 y 130 . Asimismo, fueron frecuentes las manifestaciones políticas y armadas de los integrantes del propio régimen; particularmente, las de los militares que habían sido desplazados de los principales cargos públicos o de los negocios asociados a éstos. Sobre la imposibilidad de catalogarlos de manera unívoca, tenemos el ejemplo de la rebelión delahuertista (la "rebelión sin cabeza"), que conjuntó a personajes de los más disímbolos ideales políticos y sociales.

Durante la década de 1920, los partidos y las agrupaciones que participaron en el escenario político del país provenían de raíces de la más diversa índole (comunismo, fascismo, cooperativismo, laborismo, liberalismo), y tuvieron muy distintos grados de influencia y articulación. Los que he desarrollado en este trabajo, aquéllos considerados como de derecha, se caracterizaron por su oposición al Estado; fundamentalmente, por lo que consideraban como una política persecutoria y contraria a los derechos de los creyentes católicos para profesar su religión con libertad: antes de la Constitución de 1917, por las Leyes de Reforma, y, después de expedido el texto constitucional, por los artículos que consideraban atentatorios (el 3, 24, 27 y 130, principalmente). Una oposición que se fue integrando, poco a poco, el transcurso de la primera mitad de la década, participando en los procesos electorales o en la movilización pacífica, pero que estallaría, en la segunda década, en una guerra civil (de la cual la Iglesia se deslindó): la Cristiada, que tendría enormes costos humanos y materiales para el país. A diferencia de las organizaciones de izquierda actuantes durante esos años, las de derecha carecieron prácticamente de vínculos internacionales; al menos de manera formal, pues la pertenencia de la jerarquía eclesiástica a un poder externo, Roma, no definió su campo de acción.

Los personajes más activos en este proceso fueron unos cuantos, y convergieron y divergieron respecto a los objetivos anhelados, pero todos participaron incesantemente, incluso cuando varios de ellos tuvieron que partir rumbo al exilio —o morir - debido a su actividad opositora.

La construcción plena de la base institucional del Estado mexicano no fue un proceso terso e incruento. Fue una lucha entre grupos de las más variada orientación política e ideológica, y será sólo hasta principios de la década de 1930 — con la presencia de una fuerza partidaria hegemónica, el partido oficial, que dominó a la mayor parte de la actividad política- que esto hallará un cauce cada vez más amplio.

La historiografía acerca de los partidos políticos y las organizaciones sociales ha enfatizado el estudio de la presentación de los programas y las propuestas, así como las formas de organización de las diversas corrientes políticas, y ha marginado muchas veces la acción específica de personas concretas, sin las cuales la explicación de los procesos políticos y sociales 
queda incompleta. La actuación histórica de múltiples personajes — cada uno de los cuales podría ser objeto de una biografía y ser englobados en su participación en las agrupaciones aquí estudiadas - nos acerca a un mundo más concreto de ese primer plano de su obrar político, a partir del cual se abre el análisis en torno al impacto específico de su acción transformadora, en este caso, desde la perspectiva de la crítica y el combate a un orden institucional definido desde finales de la Revolución, y vigente hasta la fecha.

\section{REFERENCIAS}

\section{Archivos}

AGN. Archivo General de la Nación, México.

DGG. Dirección General de Gobierno.

DIPS. Dirección de Investigaciones Políticas y Sociales.

AMGM. Archivo Manuel Gómez Morín. ITAM, México.

CDEHM Carso. Centro de Estudios de Historia de México, Carso.

NAW/Department of State. National Archives Washington, Records of the Department of State Relating to Internal Affairs of Mexico, 1910-1929.

\section{Hemerografía}

Cooperación. Órgano de la Academia de Estudios Sociales y Políticos del Partido Cooperatista Nacional. 1922.

El Universal. 1927-1927.

El Sol de México. Marzo de 1925.

\section{Bibliografía}

Adame Goddard, Jorge, El pensamiento político y social de los católicos mexicanos, 1867-1914, México, unAm, 1981.

Aspe Armella, María Luisa, La formación social y politica de los católicos mexicanos, México, UIA, Imdosoc, 2008.

Barbosa Guzmán, Francisco, "La cooperativa católica de ahorros y préstamos, sistema Raiffeisen, Jalisco 1910-1924”, en Catolicismo social en México, Manuel Ceballos (coord.), tomo II, México, Imdosoc, 2005, pp. 193-240.

Bartra, Roger, La democracia ausente, México, Grijalbo, 1986.

Barrón, Luis, "Conservadores liberales: Luis Cabrera y José Vasconcelos, reaccionarios y tránsfugas de la Revolución”, en Conservadurismo y derechas en la historia de México, Erika Pani (coord.), México, Fondo de Cultura Económica, Conaculta, 2009, pp. 435-466.

Blancarte, Roberto, "Modernidad, secularización y religión; la Iglesia católica, el Estado y la sociedad mexicana en el umbral del siglo xxı", en México a fines de 
siglo, José Joaquín Blanco y José Woldenberg (comps.), tomo II, México, 1993, Fondo de Cultura Económica, Conaculta, pp. 152-188.

Braderman, Eugene, "A study of political parties and politics in Mexico since 1980", tesis de doctorado, University of Illinois, 1938.

Casasola, Gustavo, Historia gráfica de la Revolución mexicana, tomo IV, México, Trillas, 1960.

Collado, Carmen (coord.), Las derechas en el México contemporáneo, México, Instituto Mora, 2015.

Dooley, Francis Patrick, Los cristeros, Calles y el catolicismo mexicano, México, SepSetentas, 1976.

García Cantú, Gastón, El pensamiento de la reacción mexicana. Historia documental. Tomo II (1869-1926), México, UnAM, 1994.

García Ugarte, Marta Eugenia, "Los católicos y el presidente Calles", Revista Mexicana de Sociología 3, 1995, pp. 131-156.

DOI: https://doi.org/10.2307/3540865

Guerra, François-Xavier, "Las elecciones legislativas de la Revolución mexicana. 1912”, Revista Mexicana de Sociología 2, 1990, pp. 241-276.

DOI: https://doi.org/10.2307/3540728

José Valenzuela, Georgette, El relevo del caudillo, México, El Caballito, 1982.

José Valenzuela, Georgette, “Ángel Flores. ¿Candidato de la reacción?”, en Estadistas, caciques y caudillos, Carlos Martínez Assad (coord.), México, unAm, 1988, pp. 205-242.

José Valenzuela, Georgette, "Entre el poder y la fe. El Partido Nacional Cooperatista, ¿un partido católico en los años veinte?", en El camino de la democracia en México, VVAA, México, agn, unAm, Cámara de Diputados, 1998, pp. 199-220.

José Valenzuela, Georgette, La campaña presidencial de 1923-1924 en México, México, INEHRM, 1998.

Lida, Clara, Ernesto Bohoslavsky y David Jorge, Las derechas iberoamericanas. Desde el fin de la Primera Guerra hasta la Gran Depresión, México, El Colegio de México, 2019.

Loaeza, Soledad, "Conservar es hacer patria. (La derecha y el conservadurismo mexicano en el siglo xx)", Nexos 64, 1983, pp. 29-39.

Mac Gregor Campuzano, Javier, Imaginar el futuro. Partidos nacionales y programas políticos en México, 1918-1928, México, unM-Iztapalapa, 2016.

Mac Gregor Campuzano, Javier, "Constitución, nueva ley electoral y viejas costumbres: elecciones y representación política”, en La tradición constitucional en México, 1808-1940, Catherine Andrews (coord.), México, CIDE, SRE, AGN, 2017, pp. 441-465.

Meyer, Jean, La cristiada. Vol. 1. La guerra de los cristeros, México, Siglo XXI editores, 1980.

Meyer, Jean, La cristiada. Vol. 2. El conflicto entre la iglesia y el estado, 1926-1929, México, Siglo XXI editores, 1974.

O’Dogherty, Laura, "Dios, Patria y Libertad. El Partido Católico Nacional", en Catolicismo social en México, Manuel Ceballos (coord.), tomo II, México, Imdosoc, 2005, pp. 104-149. 
O’Dogherty, Laura, "El Partido Católico Nacional. Las instituciones liberales al servicio de la restauración católica", en Partidos, facciones y otras calamidades. Debates y propuestas acerca de los partidos políticos en México, siglo XIX, Alfredo Ávila y Alicia Salmerón (coords.), México, FCE, Conaculta, unAM, 2012, pp. 192-236.

Olivera Sedano, Alicia, Aspectos del conflicto religioso de 1926 a 1929. Sus antecedentes y consecuencias, México, SEP, 1987.

Pérez Méndez, Marco A., "La Unión Nacional de Padres de Familia: una oposición conservadora al laicismo en la educación", en Las derechas en el México contemporáneo, Carmen Collado (coord.), México, Instituto Mora, 2015, pp. 111-186.

Pérez Montfort, Ricardo, "Tradición, anticomunismo y nacionalismo en el México de los años veinte (1922-1929)", en Las derechas iberoamericanas. Desde el fin de la Primera Guerra hasta la Gran Depresión, México, El Colegio de México, 2019, pp. 281-318.

Ulloa, Berta y Joel Hernández (coords.), Planes en la Nación Mexicana, Libros 7 y 8 , México, El Colegio de México, Senado de la República, 1987.

Ramos Pedrueza, Rafael, La lucha de clases a través de la historia de México. Revolución democrática burguesa, México, T.G.N., 1941.

Salazar, Pedro, "Longeva, parchada y deformada: ¿qué hacer en 2017 con la Constitución de 1917?", Nexos, febrero de 2016 (consultado en línea).

Toro, Alfonso, La Iglesia y el Estado en México, México, T.G.N., 1927.

Valadés, José, Historia general de la Revolución mexicana, vol. VII, México, Gernika, 1985.

Valdez, César E., "La Liga Nacional de Defensa de la Libertad Religiosa desde los ojos del Estado mexicano”, Con-temporánea 9, 2018, pp. 7-17. 